\title{
Antiproliferative and Antimicrobial Activities of Citrus limon (L.) Burm. f. Stem Bark Extract
}

\author{
${ }^{* 1}$ K.M. Salawu, ${ }^{1}$ A.A. Oyerinde and ${ }^{2}$ R. H. Bello \\ ${ }^{1}$ Department of Pharmacognosy and Drug Development, University of Ilorin \\ 2Department of Pharmaceutical Microbiology and Biotechnology, University of Ilorin \\ [Corresponding Author: Email: pharmmks@yahoo.com]
}

\begin{abstract}
Citrus limon is traditionally use for the treatment of several ailments including infectious diseases. This study was designed to evaluate antiproliferative and antimicrobial activities of Citrus limon stem bark extract. The plant material was collected, authenticated, air-dried and pulverized. Two hundred grams of powdered plant material was extracted into distilled methanol by cold maceration and the extract was concentration in a vacuo. The extract was subjected to in vitro phytochemical screening and bioassays including; antiproliferative assay (Sorghum bicolor radicle and Allium cepa root growth inhibitory assays) and antimicrobial susceptibility against Escherichia coli, Staphylococcus aureus, Citrobacter ferundii and Candida albicans. Phytochemical evaluation detected the presence of alkaloids, flavonoids and cardiac glycoside in the extract. The extract displayed concentration-dependent antiproliferative activity with an $\mathrm{IC}_{50}$ of $1.10 \pm 0.07$ and $0.62 \pm 0.04 \mathrm{mg} / \mathrm{mL}$ compared to cyclophosphamide $\left(\mathrm{IC}_{50}\right.$ of $0.17 \pm 0.02$ and $0.83 \pm 0.08$ $\mathrm{mg} / \mathrm{mL}$ ) for Sorghum bicolor radical growth and Allium cepa root growth inhibitory assays, respectively. The extract displayed antimicrobial activity with the highest activity against Escherichia coli and Citrobacter ferundii with activity indices of 0.68 and 0.59 , respectively compared to gentamicin. Citrus limon stem bark extract displayed antiproliferative and antimicrobial activities.
\end{abstract}

Keywords: Citrus limon, Antiproliferative, Antimicrobial, Escherichia coli, Citrobacter ferundii

\section{INTRODUCTION}

Plants are important sources of medicines from prehistoric times (Rather et al., 2020) and are valuable in the discovery of about $70 \%$ of all chemotherapeutic agents (antimicrobial and anticancer agents) currently in used (Davison and Brimble, 2019). Infectious diseases are the primary cause of public health concern and they account for over 17 million deaths globally each year (WHO, 2019). In many developing countries, medicinal plants have been helpful for the management of infectious diseases. However, the recent emergence of resistance to commonly used antibiotics has necessitated the need to identify natural products that may serve as a lead compound in the discovery of new antimicrobial chemotherapeutic agents.

Citrus limon (L.) Burm. f. belongs to rutaceae family and it is commonly known for its edible fruit that is consumed as food and medicine. Several parts of the plant have been reported to display different activities such as anti-inflammatory, antioxidant and antiparasitic activities (KlimekSzczykutowicz et al., 2020). Hence, this study was carried out to examine antiproliferative and antimicrobial activities of $C$. limon stem bark as a means to identify if the plant material can be further evaluated for the discovery of antiproliferative and antimicrobial chemotherapeutic agents.

\section{MATERIALS AND METHODS Plant Collection and Preparation}

The stem bark, leave and floral parts of $C$. limon (L.) Burm was collected from Fiditi forest in Afijio Local Government Area of Oyo State, South-West, Nigeria and authenticated at the Forest Herbarium in Forestry Research Institute of Nigeria (FRIN), Ibadan where a voucher number (FHI: 110008) was issued. The plant's stem bark was air-dried and pulverized. Two hundred grams $(200 \mathrm{~g})$ of the powdered plant material was extracted into distilled methanol by cold maceration over $72 \mathrm{~h}$, filtered and 
concentrated in vacuo. The dried extract was refrigerated at $4^{\circ} \mathrm{C}$ until needed for further studies.

\section{Qualitative Phytochemical Analysis}

The extract was evaluated for the presence of saponins, tannins, alkaloids, anthraquinones, cardiac glycosides, flavonoids and terpenoids using phytochemical screening protocol described by Evans (2009).

\section{Antiproliferative Assays}

Sorghum bicolor Radical Growth Inhibitory Assay

Viable seeds of Sorghum bicolor were used in this assay. Two hundred (200) mg of extract was dissolved in $20 \mathrm{~mL}$ of $5 \%$ DMSO (Sigma-Aldrich, Germany) to achieve $20 \mathrm{~mL}$ of $10 \mathrm{mg} / \mathrm{mL}$ stock solution. Thereafter, $10 \mathrm{~mL}$ of $2.50,0.63,0.16$ and $0.04 \mathrm{mg} / \mathrm{mL}$ were prepared by serial 1 in 2 dilutions of $10 \mathrm{~mL}$ of stock solution. The same concentration as the extract was prepared for cyclophosphamide (positive control). The different concentrations of the extract $(10 \mathrm{~mL})$ were added into different petri-dish already lined with cotton wool and filter paper. Ten seeds were spread on the filter paper in each petri-dish, thereafter the plates were incubated in a dark cupboard at room temperature and the lengths of the radicle emerging from the seeds were measured after $96 \mathrm{~h}$ incubation. The negative control test group contained seeds treated with $10 \mathrm{~mL}$ of $5 \%$ DMSO in distilled water (Ayinde and Agbakwuru, 2010). The experiment was repeated in three replicates for all concentrations and controls. The radicle lengths were measured and recorded in millimetres. The percentage of radical growth inhibition was calculated using the formula;

$$
\% \text { growth inhibition }=\frac{(A-B)}{A} \times 100
$$

Where: $A=$ the mean length of untreated.

$B=$ the mean length of treated with plant extract.

\section{Allium cepa Root Growth Inhibitory Assay}

Allium cepa root growth inhibition was determined using a method described by Akinboro and Bakare (2007). Clean A. cepa bulbs (50 $\pm 10 \mathrm{~g})$ were incubated at room temperature in the dark for 24-36 $\mathrm{h}$ until the roots have grown to approximately $2-3 \mathrm{~cm}$ length. Two hundred (200) $\mathrm{mg}$ of extract was dissolved in $20 \mathrm{~mL}$ of $5 \%$ DMSO (Sigma-Aldrich, Germany) to achieve 20 $\mathrm{mL}$ of $10 \mathrm{mg} / \mathrm{mL}$ stock solution. Thereafter, 10 $\mathrm{mL}$ of $2.50,0.63,0.16$ and $0.04 \mathrm{mg} / \mathrm{mL}$ were prepared by serial 1 in 2 dilutions of $10 \mathrm{~mL}$ of stock solution. The same concentration as the extract was prepared for cyclophosphamide (positive control), different concentrations were poured into different petri-dish and the base of each of three $A$. cepa bulbs were placed on a Petri-dishes containing each extract $(0.04$ $10.00 \mathrm{mg} / \mathrm{mL}$ ). The same concentrations were prepared for cyclophosphamide (positive control), while the negative control bulbs were treated with $20 \mathrm{~mL}$ of $5 \%$ DMSO in distilled water. The root lengths were measured at 0 and $96 \mathrm{~h}$ for each concentration of extract and control. The percentage root growth inhibition after treating with extract/cyclophosphamide at $96 \mathrm{~h}$ was determined (Akinboro and Bakare, 2007) using the formula;

$$
\% \text { growth inhibition }=\frac{(\mathrm{A}-\mathrm{B})}{\mathrm{A}} \times 100
$$

Where: $A=$ the mean length of untreated.

$B=$ the mean length of treated with plant extract.

\section{Determination of Antimicrobial Activity Test Organisms}

Clinical isolates of bacteria (Escherichia coli, Staphylococcus aureus, Citrobacter ferundii) and fungi (Candida albicans) were used as test organisms to determine the antimicrobial potential of $C$. limon stem bark extract. Discrete colonies from overnight culture were picked and emulsified in $5 \mathrm{~mL}$ sterile normal saline, votexed and visually compared to 0.5 McFarland turbidity scale to yield an approximate final concentration of $1.5 \times 10^{8}$ and $2.0 \times 10^{6}$ colony forming units 
(CFU/mL) for bacteria (Baker et al., 1983) and fungus (Ado et al., 2013), respectively. This turbidity scale was prepared by adding $9.6 \mathrm{~mL}$ of $1 \%$ aqueous solution of barium chloride in $0.4 \mathrm{~mL}$ of $1 \%$ sulphuric acid giving the approximate microbial density (Baker et al., 1983).

\section{Antimicrobial Susceptibility Assay}

Antimicrobial assay was performed using the disc diffusion technique earlier described by Usman et al., (2007). A stock solution (50 mg/mL) of the test extract was prepared by dissolving $500 \mathrm{mg}$ of extract in $10 \mathrm{~mL}$ of sterile distilled water. The bacterial test strains were spread over the nutrient agar plates by using separate sterile cotton buds. The fungal strain was spread over the potato dextrose agar plates. Four concentrations $(50.00,25.00,12.50$ and 6.25 $\mathrm{mg} / \mathrm{mL}$ ) of the extract were prepared by serial dilution. Thereafter, $5 \mathrm{~mm}$ diameter discs was impregnated with $100 \mu \mathrm{L}$ of $50.00,25.00,12.50$ and $6.25 \mathrm{mg} / \mathrm{mL}$ of extract to achieve a $5,2.5$, 1.25 and $0.63 \mathrm{mg} / \mathrm{disc}$. The discs were mounted on inoculated agar and incubated. All bacterial plates were incubated at $37^{\circ} \mathrm{C}$ for $24 \mathrm{~h}$ and fungal plates at $25^{\circ} \mathrm{C}$ for $72 \mathrm{~h}$. Moreover, filter paper discs (5 mm diameter) containing standards antibiotics; gentamicin (0.04 mg/disc) and fluconazole $(0.05 \mathrm{mg} / \mathrm{disc})$ were used as positive controls. The zones of inhibition were recorded in millimetres $(\mathrm{mm})$ as the diameter of growth free zones around discs. The extract and standard antibiotics were independently tested in three replicates and the results were presented as mean $\pm S E M$. The extract is considered active against the organism upon which it showed a zone of inhibition greater than $\geq 10 \mathrm{~mm}$ (Usman et al., 2007). An estimated zone of inhibition at a concentration of control (E-ZIC) was derived from a linear regression curve using GraphPad Prism. Activity index (Al) which compares the antimicrobial activity of the extract to the positive control was calculated using the method described by (Gopalakrishnan et al., 2012). The formula below was used in calculating $\mathrm{Al}$;

$$
\mathrm{AI}=\frac{\mathrm{E}-\mathrm{ZIC}}{\mathrm{ZOI}}
$$

$\mathrm{Al}=$ Activity Index

$\mathrm{E}-\mathrm{ZIC}=$ Estimated Zone of Inhibition at Concentration of Control

$\mathrm{ZOI}=$ Zone of Inhibition of Positive Control

\section{Data Analysis}

Data obtained were analyzed using the GraphPad prism computer program. The concentration with $50 \%$ growth inhibition $\left(\mathrm{IC}_{50}\right)$ in Sorghum bicolor radical growth (SBRG) and Allium cepa root growth (ACRG) inhibitory assays were estimated from a concentration-response inhibition curve using a non-linear regression curve data analysis. The results are displayed as the mean \pm SEM of three replicates.

\section{RESULTS}

\section{Qualitative Phytochemical Screening}

Phytochemical evaluation of the crude extract of C. limon stem bark led to the identification of alkaloids, flavonoids and cardiac glycoside in the extract as shown in Table 1.

Table 1: Phytochemical analysis of Citrus limon stem bark extracts

\begin{tabular}{|c|c|c|}
\hline $\begin{array}{c}\text { BIOACTIVE } \\
\text { CONSTITUENT }\end{array}$ & $\begin{array}{c}\text { CHEMICAL } \\
\text { TEST }\end{array}$ & EXTRACT \\
\hline \multirow[t]{2}{*}{ Alkaloid } & $\begin{array}{l}\text { Wagner's } \\
\text { Meyer's }\end{array}$ & + \\
\hline & Lead acetate & + \\
\hline Flavonoids & & + \\
\hline Tannins & $\mathrm{FeCl}_{3}$ & + \\
\hline \multirow[t]{2}{*}{ Saponins } & Frothing & + \\
\hline & Emulsifying & + \\
\hline \multirow[t]{3}{*}{ Anthraquinone } & & \\
\hline & Combined & \\
\hline & Free & - \\
\hline $\begin{array}{l}\text { Cardiac } \\
\text { glycoside }\end{array}$ & Kedde & + \\
\hline \multicolumn{3}{|c|}{$\begin{array}{l}\text { Keys: - = Not detected; + = Detected } \\
\text { Antiproliferative Effect of Extract on the } \\
\text { Growth Sorghum bicolor Radicle and Allium } \\
\text { cepa Root }\end{array}$} \\
\hline
\end{tabular}




\section{Nigerian Journal of Basic and Applied Science (June, 2021), 29(1): 49-54}

The extract displayed concentration dependent antiproliferative activity with $100 \%$ SBRG inhibition at $10 \mathrm{mg} / \mathrm{mL}$ and at $0.63 \mathrm{mg} / \mathrm{mL}$ the extract displayed less than $50 \%$ inhibition compared to the standard drug that displayed up to $87 \%$ at $0.63 \mathrm{mg} / \mathrm{mL}$. Hence, the calculated IC $\mathrm{C}_{50}$ value for the extract was $1.1 \pm 0.07 \mathrm{mg} / \mathrm{mL}$ while the standard drug has an $\mathrm{IC}_{50}$ of $0.17 \pm 0.02$ $\mathrm{mg} / \mathrm{mL}$. The extract displayed only $1 / 6^{\text {th }}$ of the activity of cyclophosphamide in SBRG inhibitory assay as shown in Table 2. Similarly, in ACRG inhibitory assay, the extract displayed concentration dependent inhibitory effects with $85.07 \%$ inhibition at $10 \mathrm{mg} / \mathrm{mL}$ and $51.54 \pm 2.7 \%$ inhibition at the lowest concentration. The positive control displayed $100 \%$ inhibition at 50 $\mathrm{mg} / \mathrm{mL}$ and $46.15 \%$ inhibition at $0.63 \mathrm{mg} / \mathrm{mL}$. However, the calculated $\mathrm{IC}_{50}$ of the extract was $0.62 \pm 0.04 \mathrm{mg} / \mathrm{mL}$ compared to the standard drug with $\mathrm{IC}_{50}$ of $0.83 \pm 0.08 \mathrm{mg} / \mathrm{mL}$. The extract displayed some ACRG inhibitory effect better than the standard drug as shown in Table 2.

Table 2: Percentage inhibition and $\mathrm{IC}_{50}$ of $C$. limon stem extract on sorghum bicolor radicle and Allium cepa root growth

\begin{tabular}{ccccc}
\hline $\begin{array}{c}\text { CONC. } \\
\text { (MG/ML) }\end{array}$ & \multicolumn{2}{c}{ SBRG INHIBITORY ASSAY } & \multicolumn{2}{c}{ ACRG INHIBITORY ASSAY } \\
CLS & CTZ & CLS & CTZ \\
\hline $\mathbf{1 0 . 0 0}$ & $100.00 \pm 0.00$ & $100.00 \pm 0.00$ & $85.07 \pm 1.43$ & $100.00 \pm 0.00$ \\
$\mathbf{5 . 0 0}$ & $99.32 \pm 0.53$ & $100.00 \pm 0.00$ & $71.64 \pm 2.37$ & $100.00 \pm 0.00$ \\
$\mathbf{2 . 5 0}$ & $83.11 \pm 1.33$ & $97.97 \pm 0.57$ & $62.69 \pm 2.16$ & $97.01 \pm 1.01$ \\
$\mathbf{1 . 2 5}$ & $62.16 \pm 1.53$ & $95.27 \pm 1.73$ & $59.70 \pm 1.57$ & $50.75 \pm 2.57$ \\
$\mathbf{0 . 6 3}$ & $41.59 \pm 2.45$ & $87.02 \pm 1.58$ & $51.54 \pm 2.37$ & $46.15 \pm 1.43$ \\
IC $_{50}$ & $1.10 \pm 0.07$ & $0.17 \pm 0.02$ & $0.62 \pm 0.04$ & $0.83 \pm 0.08$ \\
(mg/mL) & & & & \\
\hline
\end{tabular}

Key: CLS= Citrus limon stem bark; CTZ = Cyclophosphamide/Positive control; SBRG = Sorghum bicolor radicle growth; $A C R G=$ Allium cepa root growth

\section{Antimicrobial Effects of the Extract on Clinical Strains of Microorganisms}

The extract displayed concentration-dependent antimicrobial activities as shown in Table 3 against $E$. coli, $S$. aureus and $C$. ferundii. The extract displayed $15 \pm 1.33,12 \pm 1.53$ and $15 \pm 1.48$ $\mathrm{mm}$ zones of inhibition at $5 \mathrm{mg} / \mathrm{disc}$ and $5 \pm 0.58$, $0 \pm 0.00$ and $9 \pm 0.56 \mathrm{~mm}$ at $0.63 \mathrm{mg} / \mathrm{disc}$, respectively. Gentamicin used as the positive control displayed $20 \pm 3.33,30 \pm 1.67$ and $24 \pm 1.33$ $\mathrm{mm}$ zone of inhibition against $E$. coli, S. aureus and $C$. ferundii, respectively at $40 \mu \mathrm{g} / \mathrm{disc}$. The extract displayed anti-fungi activity with $13 \pm 1.25$ $\mathrm{mm}$ zone of inhibition at $5 \mu \mathrm{g} / \mathrm{mL}$ and $5 \pm 0.46$ zone of inhibition at $0.63 \mathrm{mg} / \mathrm{disc}$ against $C$. albicans. Fluconazole used as the positive control displayed $22 \pm 0.00 \mathrm{~mm}$ zone of inhibition against C. albicans at $0.50 \mathrm{mg} /$ disc. The extract's estimated activities at the concentration of the standard drug suggest that the extract displayed its highest activity against $E$. coli and $C$. ferundii with an Al of 0.68 and 0.59 , respectively. However, the extract displayed weak anti-fungi activity with an Al of 0.22 as shown in Table 3 . 
Salawu et al. Antiproliferative and Antimicrobial Activities of Citrus limon (L.)...

Table 3: Mean zones of Inhibition $(\mathrm{mm})$ of different concentration of $C$. limon stem bark extract against different microorganisms

\begin{tabular}{ccccc}
\hline \multirow{2}{*}{ CONC. (mg/disc) } & \multicolumn{4}{c}{ ZONE OF INHIBITION (mm) } \\
& E. coli & S. aureus & C. ferundii & C. albicans \\
\hline $\mathbf{5 . 0 0}$ & $15 \pm 1.33$ & $12 \pm 1.53$ & $15 \pm 1.48$ & $13 \pm 1.25$ \\
$\mathbf{2 . 5 0}$ & $12 \pm 0.46$ & $10 \pm 0.76$ & $14 \pm 0.77$ & $10 \pm 0.88$ \\
$\mathbf{1 . 2 5}$ & $8 \pm 0.73$ & $8 \pm 1.24$ & $12 \pm 0.93$ & $7 \pm 0.57$ \\
$\mathbf{0 . 6 3}$ & $5 \pm 0.58$ & $0 \pm 0.00$ & $9 \pm 0.56$ & $5 \pm 0.46$ \\
E-ZIC & 13.61 & 10.39 & 14.18 & 4.91 \\
Positive Control & $20 \pm 3.33^{+}$ & $30 \pm 1.67^{+}$ & $24 \pm 1.33^{+}$ & $22 \pm 0.00^{++}$ \\
Activity Index (Al) & 0.68 & 0.35 & 0.59 & 0.22 \\
\hline
\end{tabular}

Keys: E-ZIC= Estimated Zone of Inhibition at Concentration of Control; + = Zone of Inhibition of gentamicin at $0.04 \mathrm{mg} / \mathrm{disc} ;{ }^{++}=$Zone of Inhibition of fluconazole at $0.005 \mathrm{mg} / \mathrm{disc}$

\section{DISCUSSION}

The extract of Citrus limon stem bark tested positive for the presence of alkaloids, flavonoids and cardiac glycoside similar to constituents present in leave extract Citrus limon (Ewansiha et al., 2016). The extract displayed growth inhibitory effect on Sorghum bicolor radical $(1.1 \pm 0.07$ $\mathrm{mg} / \mathrm{mL})$ and Allium cepa root $(0.62 \pm 0.04 \mathrm{mg} / \mathrm{mL})$ however, lesser compared to cyclophosphamide. This is the first report of bicolor radicle and Allium cepa root growth inhibitory activity of C. limon stem bark extract.The positive growth inhibitory effect of the extract suggests that the plant may inhibit tumour growth thereby complementing earlier report of the cytotoxic effects of $C$. limon stem bark against cancer cell line (Ajaiyeoba et al., 2016). Several morphological parts of $C$. limon have been reported to demonstrate antimicrobial activities including essential oil obtained from fruit rind that was reported to showed considerable antioxidant and antimicrobial properties (Ifesan et al., 2013). In another earlier report, the stem back of $C$. limon was tested against and $S$. aureus, $C$. albicans and $B$. subtilis the extract only showed activity against Staphylococcus aureus (Musa et al., 2017). In this current study, the extract displayed highest antimicrobial activity against $E$. coli and C. ferundii and lesser activity against $S$. aureus and $C$. albicans. This work corroborates earlier reports of anti-S. aureus activity of the extract and further observed that the extract is capable of higher antimicrobial activities against $E$. coli and C. ferundii.

\section{CONCLUSION}

Methanol extract of Citrus limon stem bark contains alkaloids, flavonoids and cardiac glycoside and displayed antiproliferative effects and antibacterial activities against Escherichia coli and Citrobacter ferundii.

\section{ACKNOWLEDGEMENTS}

Appreciation to Mr. Yekin Kolawole who took me to the plant at Fiditi forest in Afijio Local Government Area of Oyo State, South-West, Nigeria.

\section{REFERENCES}

Ado, A., Ajibade, G.A., \& Maikaje, D. B. (2013). Fermentation Potentials of Citrus Limon and Hibiscus Sabdariffa Juice Extracts. Nigerian Journal of Chemical Research, 18: 11-18.

Ajaiyeoba, E. O., Salawu,K. M., Ogbole, O. O., \& Adeniji, J. A. (2016). Radical scavenging and cytotoxicity evaluation of eight extracts of Citrus limon and Citrus aurantifolia. Nigerian Journal of Natural Products and Medicine, 20:121-127.

Akinboro, A., \& Bakare, A. A. (2007). Cytotoxic and genotoxic effects of aqueous extracts of five medicinal plants on Allium cepa Linn. Journal of Ethnopharmacology, 112(3):470-475. 


\section{Nigerian Journal of Basic and Applied Science (June, 2021), 29(1): 49-54}

Ayinde, B. A., \& Agbakwuru, U. (2010). Cytotoxic and growth inhibitory effects of the methanol extract Struchium sparganophora Ktze (Asteraceae) leaves. Pharmacognosy magazine, 6(24): 293.

Baker, C. N.,Thornsberry, C., \& Hawkinson, R. W. (1983). Inoculum standardization in antimicrobial susceptibility tests: evaluation of the overnight agar cultures and the rapid inoculum standardization system. Journal of Clinical Microbiology, 17: 450-457.

Davison, E. K., \& Brimble, M. A. (2019). Natural product derived privileged scaffolds in drug discovery.Current opinion in chemical biology, 52:1-8.

Evans, W. C. (2009). Trease and evans' pharmacognosy E-book: Elsevier Health Sciences.

Ewansiha, J. U., Garba, S. A. Musa,G., Daniyan, S. Y., Busari,M. B., Innalegwu, D. A., \& Doughari, J. H. (2016). Preliminary phytochemical and Antimicrobial Activity of Citrus $x$ limon (L) Burm. f.(lemon) leaf extract against some pathogenic microorganisms. Journal of Applied Life Sciences International, 6(4):1-10.

Gopalakrishnan, S., Rajameena, R., \& Vadivel, E. (2012). Antimicrobial activity of the leaves of Myxopyrum serratulum AW Hill. International Journal of Pharmaceutical Sciences and Drug Research, 4: 31-34.

Ifesan, B. O. T., Fashakin,J. F., Ebosele, F., \& Oyerinde, A. S. (2013). Antioxidant and antimicrobial properties of selected plant leaves.European Journal of medicinal plants, 3(3): 465-473.

Klimek-Szczykutowicz, M., Szopa, A., \& Ekiert, H. (2020). Citrus limon (Lemon) Phenomenon-A Review of the Chemistry, Pharmacological Properties, Applications in the Modern Pharmaceutical, Food, and Cosmetics
Industries, and Biotechnological Studies. Plants, 9 (1):119.

Musa, A. Y., Okoro B. C., Abubakar M. N., \& llesanmi E.(2017). Phytochemical Constituents, Thin Layer Chromatography and Antimicrobial Activity of Methanol Extract of the Stem and Leave of Citrus Limon (L). International Journal of Biochemistry, Biophysics \& Molecular Biology, 2 (4):3135.

World Health Organization (WHO) (2019). Global Health Risks. Mortality and burden of disease attributable to selected major risks. Geneva: WHO. [Accessed Mar 2020].

Available

from: https://www.who.int/healthinfo/glob

al_burden_disease/GlobalHealthRisks_re port_full.pdf.

Rather, L. J., Mohammad F. A., \& Qing L. (2020). Recent Advances in the Insect Natural Product Chemistry: Structural Diversity and Their Applications. In Natural Materials and Products from Insects: Chemistry and Applications, 6794.

Usman, H., Abdulrahman, F. I., \& Ladan, A. H. (2007). Phytochemical and antimicrobial evaluation of Tribulus terrestris L.(Zygophylaceae). Growing in Nigeria. Research Journal of Biological Sciences, 2(3):244-247. 